\begin{tabular}{|c|c|}
\hline \multirow{3}{*}{ 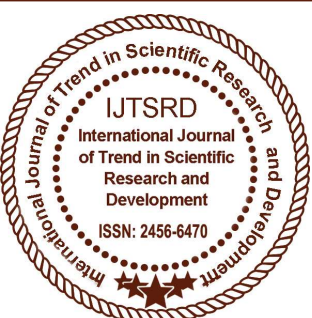 } & $\begin{array}{l}\text { International Journal of Trend in Scientific } \\
\text { Research and Development (IJTSRD) }\end{array}$ \\
\hline & International Open Access Journal \\
\hline & ISSN No: 2456 - 6470 | www.ijtsrd.com | Volume - 2 | Issue -4 \\
\hline
\end{tabular}

\title{
A Study of Teachers Role for Higher Secondary Students Psychological Problems
}

\author{
Mrs. N. Gayathiri ${ }^{1}$, Mr. K. Somasundaram ${ }^{2}$ \\ ${ }^{1}$ M.Ed. Student ${ }^{2}$ Assistant Professor \\ RVS College of Education, Coimbatore, India
}

\begin{abstract}
Research has focused predominantly on how teachers role affect students psychology problems on evidence that a broad range of attitudes and behaviors are equally important to their long-term success. We find that higher secondary teachers have large effects on self-reported measures of students self-efficacy in happiness and behavior in class. Students attitudes and behaviors are predicted by teaching practices most proximal to these measures, including teachers emotional support and classroom organization. However, teachers who are effective at improving test scores often are not equally effective at improving students attitudes and behaviors. These findings lend empirical evidence to well-established theory on the multidimensional nature of teaching and the need to identify strategies for improving the full range of teachers skills.
\end{abstract}

\section{INTRODUCTION}

Adolescence can be a stressful time for students, parents and adults who work with teens. students are dealing with the challenges of going through puberty, meetings changing expectations and coping with new feelings. Many also worry about moving from an elementary to a middle or junior high school. And some kids may have to deal with things that their peers don't have to face such as the death of a family member or moving to a new town. Most students meet these challenges successfully and grow into healthy adults while others have a harder time coping with their problems. During adolescence, the onset of psychological disorders may be fast (days of week) or slow (months or years) depending in part on the nature of social adversities. What the exact negative Psychological effects are and why the time of onset varies following exposure to negative circumstances, remain almost entirely unknown. An important assumption is that events and difficulties carry a latent and undesirable psychological construct (such as personal threat or negative impact to the self) that can be inferred from a detailed recall of the social characteristics of the experience. Recent advances in neuro sciences have opened up possibilities of characterizing in a more direct way the intermediate mental and neural processes responsible for organizing behavioral responses to different forms of adversity. Life events are defined as discrete experiences that disrupt an individuals usual activities, causing a substantial change and readjustment. Examples of life events include marriage, divorce, illness or injury and changing or losing a Job. In the literature on Stress, Life events have been traditionally considered as are type of Stress or along with chronic strain consoling stressful circumstances such as living with disability or poverty). Stress is an inferred internal state. Because no single biological parameter can adequately inform on a stressful condition and no single stress response is present in all stress related situations, there are many definitions of stress. A general distillation of the literature suggests that stress denotes a real or perceived perturbation to an organisms psychological homeostasis or psychological well-being. In its stress response the body uses a constellation of behavioural or physiological mechanism to counter the perturbation and return to normalcy. Events that precipitate stress (called stressors) elicit any of a number of coping mechanism or adaptive changes, including behavioural reactions, activation of the sympathetic nervous system and adrenal medulla secretions of stress hormones (e.g. Glucocorticoids and Prolactin), and mobilization of the immune system. Stress responses may involve at least one and 
perhaps several of the above systems, although none of them is by itself necessary or sufficient to denote stress. Furthermore, the absence or presence of any of these responses does not include or preclude the identification of stressful state. Stress responses have several key attribute.

Psychological distress is a major problem of present era especially for adolescent. It is true to emphasize that with advancement of science and technology everyone wants to move forward and reach on the peak of his / her success, complete others and live more luxurious life for which they struggle round o'clock. As a result they experienced high level of stress which may have adverse impact on their emotional, psychological cognitive and behavioral state. Individuals want to grow or develop and want to become perfect, their set goals about the future and face a number of problems like academic, financial, inter- personal, and parental pressure etc. in fulfilling their goals. Therefore is a need to increase level of self-efficacy, enhance perfection in work and develop positive attitudes for better fulfillment of goal and achievement. When individual fail to achieve their goals due to low level of self efficacy, maladaptive perfectionism or pessimistic attribution style, and or either curb by family or society, they experience high level of stress which lead to psychological distress and play an important role in development of different type of psychological disorder. Such as anxiety, depression, mood disorders or various physical problems like cancer, heart attack and migraines etc. Therefore, the present research is aimed to investigate the role of perfectionism, attribution styles and self efficacy in experiences of psychological distress among adolescents. Understanding of psycho- logical distress has been controversial for many years. The major dispute among students of psychological distress has been over the meaning of the concept, and about what actually is meant by the assertion that a person is psychologically distressed.

Psychological distress al lack of enthusiasm, problems with sleep (trouble falling asleep or staying asleep), Feeling downhearted or blue, Feeling hopeless about the future, feeling emotionally bored (For example, crying easily or feeling like crying) or losing interest in things and thoughts of suicide. Psychological distress as the emotional condition that one feels when it is necessary to cope with upsetting, frustrating or harmful situations. Psychological distress is the unpleasant subjective state of depression and anxiety (being tense, restless, worried irritable and afraid), which has both emotional and psycho- logical manifestations. They further added that there is a wide range of psychological distress, ranging from mild to extreme with extreme levels being considered as mental illness such as schizo affective disorder. Psychological distress is defined as a continuous experience of unhappiness, nervousness, irritability and problematic interpersonal relationships. Stress is a normal part of life and most people experience stress at one time or the other. It is an individual physical and mental reaction to environmental demands. Stress is sometimes conceptualized as environ- mental stimulus or life events that impinge on individuals. Sometimes as particular reactions to stressful events or a mismatch between demands placed on the individual and the perceive ability to cope with the demands .A certain amount of stress is necessary for survival an a moderate / optimal level of stress is normal and in many cases it is useful. And optimal level of stress is required for success in Job, achievement higher productivity and effectiveness. When stress level is extreme, and unchecked and unmanaged, can create problems in performance and can be detrimental to health and well-being of the individual.

\section{Review of Literature}

Holmes, K., Gore, J., Smith, M., \& Lloyd, A (2018) explains Declining enrolments in science, technology, engineering and mathematics (STEM) disciplines and a lack of interest in STEM careers are concerning at a time when society is becoming more reliant on complex technologies. We examine student aspirations for STEM careers by drawing on surveys conducted annually from 2012 to 2015. School students in years 3 to $12(n=6492)$ were asked to indicate their occupational choices. A logistic regression analysis showed that being in the older cohorts, possessing high cultural capital, being male, having a parent in a STEM occupation and high prior achievement in reading and numeracy, were significant. This analysis provides a strong empirical basis for school-based initiatives to improve STEM participation. In particular, strategies should target the following: the persistent lack of interest by females in some careers, improving student academic achievement in both literacy and numeracy and expanding knowledge of STEM careers, especially for students without familial STEM connections. 
Deb, S., Strodl, E., \& Sun, J. (2015) investigated the academic stress and mental health of Indian high school students and the associations between various psychosocial factors and academic stress. A total of 190 students from grades 11 and 12 (mean age: 16.72 years) from three government-aided and three private schools in Kolkata India were surveyed in the study. Data collection involved using a specially designed structured questionnaire as well as the General Health Questionnaire. Nearly two-thirds (63.5 reported stress due to academic pressure with no significant differences across gender, age, grade, and several other personal factors. About two-thirds (66 reported feeling pressure from their parents for better academic performance. The degree of parental pressure experienced differed significantly across the educational levels of the parents, mothers occupation, number of private tutors, and academic performance. In particular, students of fathers possessing a lower education level (non- graduates) were found to be more likely to perceive pressure for better academic performance. About onethirds (32.6 examination related anxiety. Academic stress was positively correlated with parental pressure and psychiatric problems, while examination-related anxiety also was positively related to psychiatric problems. Academic stress is a serious issue which affects nearly two thirds of senior high school students in Kolkata. Potential methods for combating the challenges of academic pressure are suggested. Suldo, S. M., Savage, J. A., \& Mercer, S. H. (2014) identified middle school students who were less than delighted with their lives (reported life satisfaction scores between 1 and 6 on a 7-point scale), and attempted to improve these students mental health via a 10-week group wellnesspromotion intervention developed from prior applications of positive psychology research. Complete data at baseline, post-intervention, and 6month follow-up was gathered from 55 sixth grade students who were randomly assigned to the intervention condition $(\mathrm{n}=28)$ or wait-list control ( $\mathrm{n}$ $=27$ ). Repeated measures analyses of a propensity score matched sample of 40 participants indicated a significant group by time interaction for global life satisfaction from baseline to post-intervention. Specifically, life satisfaction of students in the intervention group increased significantly, while the control group declined during the same period (although this change was not statistically significant). The intervention groups gains were maintained at follow-up, but were matched by similar gains for students in the control group. No effects of intervention group were identified in the indicators of affect or psychopathology. The improvements in life satisfaction evidenced by students in the intervention group during the first semester of middle school are important given the adjustment difficulties that often appear during this sensitive developmental period marked by biological and educational changes. Bauman, S., Toomey, R. B., \& Walker, J. L. (2013) examined associations among depression, suicidal behaviors, and bullying and victimization experiences in 1491 high school students using data from the 2009 Youth Risk Behavior Survey. Results demonstrated that depression mediated the association between bullying/victimization and suicide attempts, but differently for males and females. Specifically, depression mediated the link between traditional victimization and suicide at- tempts similarly across gender, whereas depression mediated the link between cyber victimization and suicide attempts only for females. Similarly, depression mediated the link between traditional bullying and suicide attempts for females only. Depression did not mediate the link between cyber bullying and suicide attempts for either gen- der. Implications of the findings are discussed, including the importance of greater detection of depression among students involved in bullying, and the need for a suicide prevention and intervention component in anti-bullying programs. Findings suggest that bullying prevention efforts be extended from middle school students to include high school students. Sakiz, G., Pape, S. J., \& Hoy, A. W. (2012) explored the importance of perceived teacher affective support in relation to sense of belonging, academic enjoyment, academic hopelessness, academic selfefficacy, and academic effort in middle school mathematics classrooms. A self-report survey was administered to 317 seventh- and eighth-grade students in 5 public middle schools. Structural equation modeling indicated significant associations between perceived teacher affective support and middle school students motivational, emotional, and behavioral outcomes.

Muralidharan, K., \& Sundararaman, V. (2015) presented experimental evidence on the impact of a school choice program in the Indian state of Andhra Pradesh (AP) that provided students with a voucher to finance attending a private school of their choice. The study design featured a unique two-stage lottery-based allocation of vouchers that created both a studentlevel and a market- level experiment, which allows us to study both the individual and the aggregate effects 
of school choice (including spillovers). After two and four years of the program, we find no difference between test scores of lottery winners and losers on Telugu (native language), math, English, and science/social studies, suggesting that the large crosssectional differences in test scores across public and private schools mostly reflect omitted variables. However, private schools also teach Hindi, which is not taught by the public schools, and lottery winners have much higher test scores in Hindi. Further, the mean cost per student in the private schools in our sample was less than onethird of the cost in public schools. Thus, private schools in this setting deliver slightly better test score gains than their public counterparts (better on Hindi and same in other subjects), and do so at a substantially lower cost per student. Finally, we find no evidence of spillovers on public school students who do not apply for the voucher, or on private school students, suggesting that the positive impacts on voucher winners did not come at the expense of other students. Bagchi, N. N., Ganguly, S., Pal, S., \& Chatterjee, S. (2014) Tobacco use among school students and adolescents is an increasing problem world-wide, particularly in the developing countries. A cross-sectional observational study was carried out in six co- educational high schools in Kolkata, West Bengal among 526 students of 15-19 years to determine the prevalence of smoking and to find out any difference among the smokers and non-smokers regarding factors related to family relations, peer group and personal characteristics. The overall rate of smoking was found to be $29.6 \%$, mean age of initiation of smoking was earlier in males. Among smokers $75 \%$ students started smoking by 15 years. Smoking of father and peer group, family conflict and pornography addiction were found to have significant association with smoking of students. Early school health based interventions addressing these factors might help in effectively tackling this problem.

\section{Objectives of the study}

1. To create the awareness about the psychological problems to students.

2. To create the awareness to understand the psychological problems of the students by teachers.

3. To study some of the methods to overcome from psychological problems

4. To study the effect of the teachers role to suppress the psychological problem of the students.
5. To improve the students mental health, concentration, through various practice.

\section{Research Questions}

1. Is there any significance mean score difference between Gender and study of teacher role for higher secondary students psychology?

2. Is there any significance mean score difference between medium of study related factors and study of teacher role for higher secondary students psychology?

3. Is there any significance mean score difference between type of school related factors and study of teacher role for higher secondary students psychology?

4. Is there any significance mean score difference between type of family and study of teacher role for higher secondary students psychology?

5. Is there any significance mean score difference between locality and study of teacher role for higher secondary students psychology?

\section{Hypotheses}

1. There will be significant study of teacher role for higher secondary students psychology based on gender.

2. There will be significant study of teacher role for higher secondary students psychology based on medium of study.

3. There will be significant study of teacher role for higher secondary students psychology based on the type of school.

4. There will be significant study of teacher role for higher secondary students psychology student based on the type of family.

5. There will be significant study of teacher role for higher secondary students psychology based on the locality.

\section{Variables}

An independent variable is a variable that is expected to influence the dependent variables. Its value may be changed or altered, which is independent of any other variables. Also the following demographic variables were used as independent variables.

Gender (Male/Female).

Medium of study(Tamil/English).

School Type(Government/Private).

School Location (Urban/Rural).

Family (Joint/Nuclear) 
International Journal of Trend in Scientific Research and Development (IJTSRD) ISSN: 2456-6470

Dependent variable are those events which are by hypothesized as dependent on the changes in the dependent variable (A Study of Teachers Role for Higher Secondary Students Psychological Problems).

\section{Design of the study}

In the presence study Normative survey method will be adopted. Survey research employee questioner and interview to our people who pro- vide in formations about them selfs their attitude and believes demographic (Age, Gender, Income and So on) the survey method can be classified into many, but according to the objectives and hypotheses in this presence study normative survey method will be adopted.

\section{Population and Sample}

Coimbatore district is one of the district in Tamilnadu, India. Coimbatore is finest education district of Tamilnadu. It is the second largest city in Tamilnadu and one of the fastest growing cities in Tamilnadu State. For the present study the investigator select only 6 Schools from both Government and Private School around Coimbatore. Investigator selected Datas will be collected from the samples of 300 Students of various schools.

\section{Sampling Techniques}

Sampling procedure is a definite plan determined before any data are actually collected for obtaining a sample from a given population under the simple random sampling technique. This sampling method is used for selecting samples. Simple random sampling is method in which each and every element in the population has an equal chance of getting selected. The study is based on primary data which is collected from 300 school students at higher secondary level and around Coimbatore district. The sample which was collected from various college located in and around Coimbatore is shown as below.

Table 1.1

\section{List of schools used for data collection}

\begin{tabular}{|c|c|c|}
\hline $\begin{array}{c}\text { S. } \\
\text { No }\end{array}$ & $\begin{array}{c}\text { Name of the schools } \\
\text { ber }\end{array}$ & 53 \\
\hline 1. & $\begin{array}{c}\text { Alvernia Matriculation Higher } \\
\text { Secondary School, }\end{array}$ & 46 \\
\hline 2. & $\begin{array}{c}\text { Sri Ramaswamy Naidu } \\
\text { Vidyalayam Higher Secondary }\end{array}$ & 49 \\
\hline 3. & $\begin{array}{c}\text { Michael Job Matriculation Higher } \\
\text { Secondary School, Sulur, }\end{array}$ & 56 \\
\hline 4. & $\begin{array}{c}\text { Government Boys Higher } \\
\text { secondary School, Sulur }\end{array}$ & \\
\hline
\end{tabular}

\begin{tabular}{|c|c|c|}
\hline 5. & $\begin{array}{c}\text { Government Girls Higher } \\
\text { secondary School, Sulur }\end{array}$ & 54 \\
\hline 6. & $\begin{array}{c}\text { Government Higher Secondary } \\
\text { School Irugur }\end{array}$ & 42 \\
\hline
\end{tabular}

TABLE 1.2

Distribution of samples based on variables

\begin{tabular}{|c|c|c|c|c|}
\hline Category & Subgroups & $\begin{array}{c}\text { Num } \\
\text { ber }\end{array}$ & $\begin{array}{c}\text { Tot } \\
\text { al }\end{array}$ \\
\hline \multirow{2}{*}{ Gender } & Male & 174 & 58 & \multirow{2}{*}{300} \\
\cline { 2 - 4 } & Female & 126 & 42 & \\
\hline \multirow{2}{*}{$\begin{array}{c}\text { Medium } \\
\text { Study }\end{array}$} & Tamil & 207 & 69 & \multirow{2}{*}{300} \\
\cline { 2 - 4 } School Type & English & 93 & 31 & \\
\cline { 2 - 4 } & Government & 159 & 53 & \multirow{2}{*}{300} \\
\cline { 2 - 4 } & Private & 141 & 47 & \\
\hline \multirow{2}{*}{$\begin{array}{c}\text { School } \\
\text { Location }\end{array}$} & Rural & 177 & 59 & \multirow{2}{*}{300} \\
\cline { 2 - 4 } Family Type & Urban & 123 & 41 & \\
\cline { 2 - 4 } & Joint & 42 & 14 & \multirow{2}{*}{300} \\
\cline { 2 - 4 } & Nuclear & 258 & 86 & \\
\hline
\end{tabular}

\section{Research Tool}

Tool become another major consideration in an education research. The instrument employed for the collection of data required for the study of any problem is called tool. Tool employ distinction way of describing and qualifying the data the important tools of educational research include inter- view schedule, questionnaire, observation, rating scale, proficiency test, psychological tests and sociogram.

\section{Testing Hypothesis 1:}

There will be significant study of teacher role for higher secondary students psychology based on gender (Male/Female).

\section{TABLE 1.3}

\section{t- value of factors study of teacher role for higher} secondary students psychology based on gender

\begin{tabular}{|c|c|c|c|c|c|c|}
\hline $\begin{array}{c}\text { S. } \\
\text { No }\end{array}$ & Gender & N & Mean & Df & t-Value & Result \\
\hline 1 & Male & 174 & 1.2656 & & & \\
\cline { 1 - 4 } 2 & Female & 126 & 1.2209 & 299 & 2.087 & S \\
\hline \multicolumn{2}{|c|}{ Total } & 300 & 1.2483 & & & \\
\hline
\end{tabular}

The Table 1.3 shows the mean score difference in significant study of teacher role for higher secondary students psychology based on gender (Male/Female). The calculate $t$ value is statistically a significance at 0.05 levels and hence the hypotheses 1 is accepted. It can be concluded that there is a significant difference in mean score difference in significant study of 
International Journal of Trend in Scientific Research and Development (IJTSRD) ISSN: 2456-6470

teacher role for higher secondary students psychology based on gender.

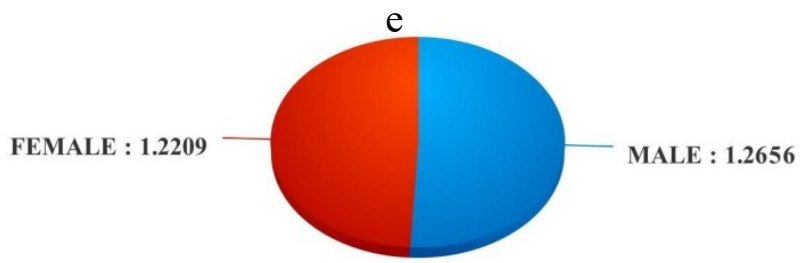

Figure 1:Relationship Between Students Gender and study of teacher role for higher secondary

Testing Hypothesis 2: students psychology

There will be a significant mean score difference in significant study of teacher role for higher secondary students psychology based on Medium of Study (Tamil/English).

TABLE 1.4

Mean Score difference and $t$ - value of factors related to significant study of teacher role for higher secondary students psychology based on Medium of Study (Tamil/English).

\begin{tabular}{|c|c|c|c|c|c|c|}
\hline $\begin{array}{c}\text { S. } \\
\text { No }\end{array}$ & Medium & N & Mean & Df & $\begin{array}{c}\text { t- } \\
\text { Value }\end{array}$ & $\begin{array}{c}\text { Re- } \\
\text { sult }\end{array}$ \\
\hline 1 & Tamil & 207 & 1.1775 & & & \\
\cline { 1 - 4 } 2 & English & 93 & 1.2335 & \multirow{2}{*}{299} & -2.897 & S \\
\hline \multicolumn{2}{|c|}{ Total } & 300 & 1.2055 & & & \\
\hline
\end{tabular}

The Table 1.4 shows the mean score difference in significant study of teacher role for higher secondary students psychology based on Medium of Study (Tamil/English). The calculate $\mathrm{t}$ value is statistically a significance at 0.05 levels and hence the hypotheses 2 is accepted. It can be concluded that there is a significant difference in mean score difference in significant study of teacher role for higher secondary students psychology based on Medium of Study.

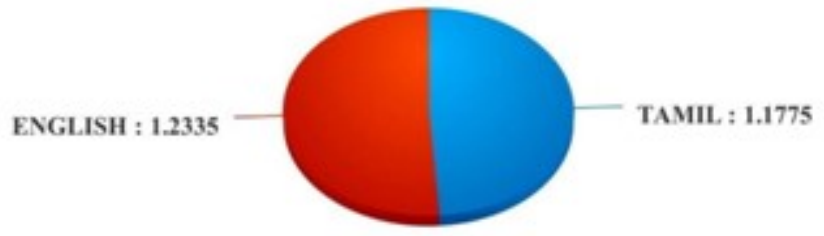

Figure 2:Relationship Between Students medium of study and study of teacher role for higher secondary students psychology

Testing Hypothesis 3:

There will be a significant mean score difference in teacher role among selected secondary students psychology based on School type (Government/ Private).
TABLE 1.5

Mean Score difference and $t$ - value of factors related to significant study of teacher role for higher secondary students psychology based on School type (Government/Private).

\begin{tabular}{|r|c|c|c|c|c|c|}
\hline $\begin{array}{r}\text { S. } \\
\text { No }\end{array}$ & School type & $\mathbf{N}$ & Mean & Df & t-Value & Re-sult \\
\hline $\mathbf{1}$ & Government & 159 & 1.2383 & & & \\
\hline $\mathbf{2}$ & Private & 141 & 1.1887 & 299 & \multirow{2}{*}{0.908} & NS \\
\cline { 1 - 4 } Total & $\mathbf{3 0 0}$ & $\mathbf{1 . 2 1 3 5}$ & & & \\
\hline
\end{tabular}

The Table 1.5 shows the mean score difference in significant study of teacher role for higher secondary students psychology based on School type (Government/Private). The calculate $t$ value is statistically no significance at 0.05 levels and hence the hypotheses 3 is rejected. It can be concluded that there is no significant difference in mean score difference in significant study of teacher role for higher secondary students psychology based on School type(Government/Private).

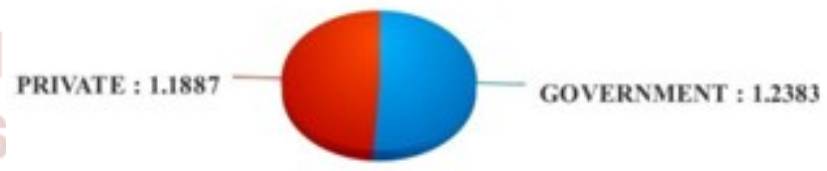

Figure 3:Relationship Between Students school type and Study of Teacher Role for Higher Secondary Students Psychology

\section{Testing Hypothesis 4:}

There will be a significant mean score difference in teacher role among selected secondary students psychology based on School Location (Rural/Urban).

\section{TABLE 1.6}

Mean Score difference and $t$ - value of factors related to significant study of teacher role for higher secondary students psychology based on School Location (Rural/Urban).

\begin{tabular}{|c|c|c|c|c|c|c|}
\hline S.No & School & $\mathrm{N}$ & Mean & Df & t-Value & Result \\
\hline 1 & Rural & 177 & 1.1690 & \multirow{3}{*}{299} & \multirow{3}{*}{-2.459} & \multirow{3}{*}{$\mathrm{S}$} \\
\hline 2 & Urban & 123 & 1.2612 & & & \\
\hline \multicolumn{2}{|c|}{ Total } & 300 & 1.2151 & & & \\
\hline
\end{tabular}

The Table 1.6 shows the mean score difference in significant study of teacher role for higher secondary students psychology based on School Location (Rural/Urban). The calculate $t$ value is statistically a significance at 0.05 levels and hence the hypotheses 4 is accepted. It can be concluded that there is a significant difference in mean score difference in 
significant study of teacher role for higher secondary students psychology based on Location (Rural/Urban).

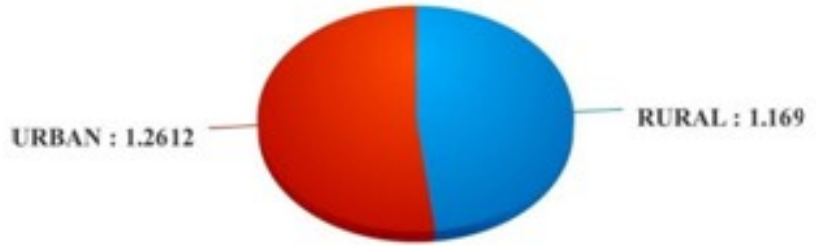

Figure 4:Relationship Between Students school location and Study of Teacher Role for Higher Secondary Students Psychology

\section{Testing Hypothesis 5:}

There will be a significant mean score difference in teacher role among selected secondary students psychology based on Family type (Joint/Nuclear).

TABLE 1.7

Mean Score difference and t- value of factors related to significant study of teacher role for higher secondary students psychology based on Family type (Joint/Nuclear).

\begin{tabular}{|c|c|c|c|c|c|c|}
\hline $\begin{array}{l}\text { S. } \\
\text { No }\end{array}$ & $\begin{array}{c}\text { Family } \\
\text { Type }\end{array}$ & $\mathbf{N}$ & Mean & Df & t-Value & Result \\
\hline 1 & Joint & 42 & 1.0690 & \multirow{3}{*}{299} & \multirow{3}{*}{$\begin{array}{l}\text { Of T } \\
-2.459\end{array}$} & \\
\hline 2 & Nuclear & 258 & 1.4612 & & & $\mathrm{~S}$ \\
\hline \multicolumn{2}{|c|}{ Total } & 300 & 1.2151 & & & \\
\hline
\end{tabular}

The Table 1.7 shows the mean score difference in significant study of teacher role for higher secondary students psychology based on School Location (Rural/Urban). The calculate $\mathrm{t}$ value is statistically a significance at 0.05 levels and hence the hypotheses 4 is accepted. It can be concluded that there is a significant difference in mean score difference in significant study of teacher role for higher secondary students psychology based on Family type (Joint/Nuclear).

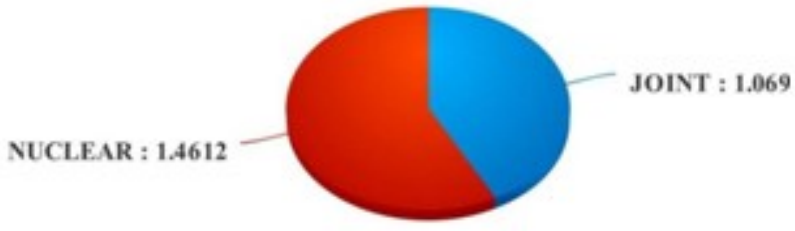

Figure 5:Relationship Between Students family type and Study of Teacher Role for Higher Secondary Students Psychology

\section{Findings of the study}

There is a significant relationship between gender and study of teachers role for higher secondary students psychological problems.

$>$ There is a significant relationship between medium of study related factors and study of teachers role for higher secondary students psychological problems.

$>$ There is no significant relationship between school type related factors and study of teachers role for higher secondary students psychological problems.

$>$ There is a significant relationship between school location and study of teachers role for higher secondary students psychological problems.

There is a significant relationship between family type and study of teachers role for higher secondary students psychological problems.

\section{Summary}

A study of teachers role for higher secondary students was studied and the findings reveal that there is a significant difference between significant study of teacher role for higher secondary students psychology with respect to gender, medium of study, school location and family type.

A study of teachers role for higher secondary students was studied and the findings reveal that there is no significant difference between significant study of teacher role for higher secondary students psychology with respect to school type.

\section{Limitations}

The study has certain limitation, which are as follows:

Only 300 students are selected as sampling for the study.

The project has been restricted to analyze and study in mobile learning and its study of teacher role for higher secondary students psy- chology.

$>$ The study is restricted to the school students of Coimbatore.

\section{Conclusion and Future Recommendations}

$>$ A Similar Study can be conducted for dissertation by taking more number of concepts and students.

$>$ The study can be conducted to other schools around Tamilnadu. 
$>$ Present survey helps to investigate the study of teacher role for higher secondary students psychology

> A similar study can also be conducted using various variables.

The conclusion is that there is a significant relationship between gender,medium of study, school location and family type on study of teachers role for higher secondary students psychological problems.

\section{Bibliography}

Augustine, L. F., Vazir, S., Rao, S. F., Rao, M. V. V., Laxmaiah, A., \& Nair, K. M. (2011). Perceived stress, life events \& coping among higher secondary students of Hyderabad, India: A pilot study. The Indian journal of medical research, 134(1), 61 .

Bagchi, N. N., Ganguly, S., Pal, S., \& Chat terjee, S. (2014). A study on smoking and associated psychosocial factors among adoles- cent students in Kolkata, India. Indian journal of public health, 58(1), 50 .

Bauman, S., Toomey, R. B., \& Walker, J. L. (2013). Associations among bullying, cyber-bullying, and suicide in high school students. Journal of adolescence, 36(2), 341-350.

Chaturvedi, D. K., Arora, N., Trivedi, P., Rastogi, R., \& Chauhan, S. (2018). Framework for Use of Machine Intelligence on Clinical Psychology to Study the effects of Spiritual tools on Human Behavior and Psychic Challenges. Journal of Image Processing and Artificial Intel- ligence, 4(1).

Deb, S., Strodl, E., \& Sun, J. (2015). Aca- demic stress, parental pressure, anxiety and mental health among Indian high school students. International Journal of Psychology and Behav- ioral Sciences, 5(1), 26-34.

Dietrichson, J., Bg, M., Filges, T., \& Klint Jrgensen, A. M. (2017). Academic interventions for elementary and middle school students with low socioeconomic status: A systematic review and meta-analysis. Review of Educational Re- search, 87(2), 243-282.

Raju, R., \& Tan, K. E. (2017). Language anxiety among ESL schools students in India. The English Teacher, (2), 18.

Srivastava, S., Pant, M., \& Agrawal, N. (2018). Psychology of adolescents: a fuzzy logic analy- sis. International Journal of System Assurance Engineering and Management, 9(1), 66-81.

Suldo, S. M., Savage, J. A., \& Mercer, S.

H. (2014). Increasing middle school students life satisfaction: Efficacy of a positive psychology group intervention. Journal of happiness studies, 15(1), 1942.

Van Rooij, E. C., Jansen, E. P., \& van de Grift, W. J. (2017). Secondary school students engagement profiles and their relationship with academic adjustment and achievement in univer sity. Learning and Individual Differences, 54, 9-19.

Varghese, N. V. (2018). Education Research and Emergence of Higher Education as a Field of Study in India. In Researching Higher Education in Asia (pp. 299-313). Springer, Singapore.

Zhang, T., Solmon, M. A., Kosma, M., Car- son, R. L., \& Gu, X. (2011). Need support, need satisfaction, intrinsic motivation, and physical activity participation among middle school stu- dents. Journal of teaching in physical education, 30(1), 51-68.

\section{APPENDICES}

\section{PROFORMA FOR BASIC DATA}

1. Name of the student :

2. Name of the School

3. Gender : Male [ ] Female [ ]

4. Medium of Instruction: Tamil [ ] English [ ]

5. School Type : Government [ ]Private [ ]

6. School Location : Rural [] Urban [ ]

7. Family type : Joint [] Nuclear [ ] 


\section{Questionnaire}

\begin{tabular}{|c|c|c|c|}
\hline $\begin{array}{l}\text { S. } \\
\text { NO. }\end{array}$ & Question & \multicolumn{2}{|c|}{ Answer } \\
\hline 1 & Is your teacher give advice in your studies? & Yes & No \\
\hline 2 & Are you getting support from teacher when you feel alone? & Yes & No \\
\hline 3 & Is your teacher helps when a money problem? & Yes & No \\
\hline 4 & Is your teacher help you when a family problems? & Yes & No \\
\hline 5 & Is your teacher helps when you are not feeling well? & Yes & No \\
\hline 6 & Is your teacher helps when you fear about Tests/Exams/Papers? & Yes & No \\
\hline 7 & Is your teacher helps for extra curricular activities? & Yes & No \\
\hline 8 & Is your teacher behaves like your parents in any tin & Yes & No \\
\hline 9 & My teacher listens carefully to me when I talk? & Yes & No \\
\hline 10 & My teacher helps me when I need help? & Yes & No \\
\hline 11 & My teacher respects me? & Yes & No \\
\hline 12 & My teacher likes having me in this class? & Yes & No \\
\hline 13 & My teacher appreciates me when I do well? & Yes & No \\
\hline 14 & My teacher criticize me when I do mistake? in Scie & Yes & No \\
\hline 15 & My teacher insults me in front of others when I do mistake? & Yes & No \\
\hline 16 & My teacher helps me to overcome from my psycholo & Yes & No \\
\hline 17 & My teacher helps me to improve my personality? & Yes & No \\
\hline 18 & Teachers give enough freedom for expressing my ow & Yes & No \\
\hline 19 & Teachers exert over control on us.? & Yes & No \\
\hline 20 & My teachers like me very much? & Yes & No \\
\hline 21 & My teachers encourage me to express my own ideas? & Yes & No \\
\hline 22 & My teachers always give lot of new information.? & Yes & No \\
\hline 23 & I often dislike to go to school because of the fear towards my teachers. & Yes & No \\
\hline 24 & My teachers encourage me to participate in all competitions & Yes & No \\
\hline 25 & $\begin{array}{l}\text { Don't students learn more ideas from psychological approach learning than } \\
\text { textbooks? }\end{array}$ & Yes & No \\
\hline 26 & I like teachers who have some sense of humour & Yes & No \\
\hline 27 & Is your teacher helps you in understanding the difficult lessons & Yes & No \\
\hline
\end{tabular}

